\title{
Can organizational change be planned and controlled? Evidence from Russian companies
}

\author{
Tatiana E. Andreeva* \\ Graduate School of Management, St Petersburg State University, St Petersburg, Russia
}

\begin{abstract}
This study explores limits of applicability of a planned change approach in Russian companies. The data on change management programmes in 59 Russian companies of various industries, regions and sizes was gathered with the help of questionnaires filled by management consultants. The study found that resulted changes often did not coincide with initial plans of change agents. Two groups of organizational elements were identified: 'uncontrollable' (those elements that changed outside of the planned change) and 'unmanageable' (those elements that did not change despite forming part of the planned change). The findings also indicate that the efficiency of the change programme was unaffected by whether the change programme plans were executed or not. The results suggest that the applicability of a planned change approach is dependent upon the organizational elements at which change interventions are targeted and that change content has to be incorporated into contingency models of change.
\end{abstract}

Keywords: planned change model; contingency approach; Russia; empirical data

Today, factors and trends such as globalization, constantly changing or even disappearing boundaries between industries, intensively changing technologies, the rise of knowledge as a driving force of competition, the appearance of new organizational forms, and mass mergers and acquisitions, all force organizations to change constantly. Both academics and company leaders agree that a company's capability to change efficiently following environmental changes, or in anticipation of them, provides a significant contribution to its successful development. Contemporary management literature offers numerous recommendations for managers on how to manage organizational change effectively. Many of these recommendations are based on a planned change model that was formalized several decades ago (Lewin 1951) and still dominates international practically oriented management literature on change (Kotter 1995; Duck 2001). However, a number of recent writers have criticized and challenged its universal applicability (Marshak 1993; Burnes 1996; Hendry 1996; Weick and Quinn 1999).

For Russian companies, the problem of managing changes efficiently is doubly relevant. On the one hand, the transition to a market economy urged most Russian organizations to adapt to new environmental conditions and fluctuations. On the other hand, most of the literature on change management that could help Russian managers to cope with this complex challenge is based on approaches developed in Western liberal

\footnotetext{
*Email: tatiana_andreeva@mail.ru
} 
market economies (Metcalfe and Afanassieva 2005; May, Puffer and McCarthy 2005). In some cases, these approaches are already being criticized in the places from which they originated. Moreover, the scope of their applicability in Russia is not yet determined. The planned change model exemplifies one such an approach for the model is widely cited in contemporary Russian management literature and used for development of recommendations for Russian managers, often without any mention of the limits of its applicability to Russian context.

That is why we posit that Russian companies can serve as a fertile ground for the study of applicability of a planned change model. The paper presents findings from a research project on change management in Russian companies. The paper is structured as follows. We commence with an overview of the key assumptions of the planned change model and its associated criticisms, and follow this with a discussion of the current situation with regards to change management in Russia. We proceed to present our research hypotheses and research strategy, including data collection methods and sample characteristics. In the final sections of the paper, the report provides a discussion and critique of these findings and considers their implications for further research and change management practice, both in Russia and internationally.

\section{Theoretical grounds and hypotheses}

\section{Ideas about planning and controlling change in management literature}

Change management as a separate field of studies is usually said to have begun around 60 years ago with what we know now as planned change model or Lewin's model. Despite being chronologically one of the first in the field, this model remains extremely influential. Many authors claim that Lewinian understanding of organizational change process has been dominating organizational science for decades (Burnes 1996; Hendry 1996; Weick and Quinn 1999) and remains the most widely cited recipe for implementing changes, especially in business periodicals (Sevier 2003).

The planned change model is rooted in Kurt Lewin's work in which he offered a threestep model for implementing change successfully: unfreezing, moving and refreezing (Lewin 1951). Later on, this idea became one of the cornerstones of organization development theorizing (Blake and Mouton 1969; French and Bell 1995) and was widely used by various authors for development of recommendations for managers on how to implement change (Lippitt et al. 1958; Cummings and Huse 1989; Kotter 1995; Armenakis and Bedeian 1999). The writings within this discourse are based on the assumption that 'an organization exists in different states at different times and that planned movement can occur from one state to another' (Cummings and Huse 1989, 51). That is, the approach is based on the assumption that a company leader or change agent possess enough power and influence to fully bring their change plans into reality. Further, the approach assumes that change leaders are rational individuals capable of analysing and foreseeing future consequences of their decisions and hence of developing thorough plans in order to implement these decisions.

Other conceptual models of organizational change have been developed, for example, the organization life cycle model (Greiner 1972) and the punctuated equilibrium model (Tushman, Newman and Romanelli 1986). These models, which tend to focus on macrolevel issues as compared to the planned change model, attempt to explain why organizations undergo transformations. However, their micro-level, change implementation recommendations are usually based on similar assumptions about the possibility to foresee events and plan changes, and to control for the exact implementation of plans. For example, Tushman, Newman and Romanelli (1986) offer two approaches for the 
implementation of revolutionary and evolutionary changes but both of them still rely on the assumption of pre-planned action implementation.

Despite remaining very influential, the planned change model has been criticized in academic literature since the 1980s. One of the key arguments that has been levelled against this model concerns its assumption that organizations operate under fairly stable conditions and can move from one stable state to another in a pre-planned manner (Burnes 1996; Weick and Quinn 1999). Its view of organizational change as a planned or at least sufficiently predictable process that is controlled largely by the company leader is claimed to be unrealistic in a contemporary fast-changing, chaotic world. The assumption about the crucial role of managers and change agents as rational and powerful planners is also heavily challenged in the light of current understanding of organizations as complex systems (Dooley and Van de Ven 1999). Another criticism of the planned change model concerns the shortage of substantial empirical data to support its recommendations (Hendry 1996), which is surprising, taking into account the model's age and its wide-scale application.

Based on these criticisms, a new wave of publications on organizational change has emerged over the past 15 years. This literature incorporates a notion of incomplete predictability and controllability of change (Marshak 1993; Van de Ven and Poole 1995; Weick 1998; Palmer and Dunford 2002; Huy and Mintzberg 2003). A number of new concepts have been developed, like the emergent change model (Weick and Quinn 1999) and the self-organization/chaos model (Thietart and Forgues 1995; Lichtenstein 2000). Theorists associated with these models argue that managers' capability to plan and control change is very restricted. Yet, the empirical studies within this new stream of thought are in short supply; it is probably for this reason that such approaches tend to be neglected in practical books for managers that, in the main, continue to advocate the planned change model (Duck 2001).

The preceding discussion raises questions about the concepts HRD managers should use when designing change management programmes in their organizations. The need for more empirical data that could inform their choice is evident. However, we consider it futile to attempt to prove empirically which of the models is 'correct' despite the fact that organizational change theorists often assume that the approach to change management they propose fits all organizations under all circumstances (Burnes 1996). Arguably, this universalistic focus of many change management recommendations is one of the reasons for so frequently reported failures of change programmes (Beer, Eisenstat and Spector 1990). Thus, we support the contingency approach to change management, which posits that the efficiency of certain change management practices will depend upon the situation to which they are applied (Stace and Dunphy 1991; Berger 1992; Marshak 1993). This is why we explore the stance that it is appropriate to investigate the limits of the planned change model's applicability rather than seeking to 'prove' or 'disprove' its efficacy. A wide range of factors can be considered as potential contingencies that may influence applicability and efficiency of certain change management practices, including national culture, organizational sector, organizational culture and management style (Stace and Dunphy 1991; Marshak 1993; Michailova 2000). Within the remit of this paper, we focus on country-specific issues, taking the Russian context as an example.

\section{Russian premise for organizational change}

All organizations at some time or another face an acute need for organizational change but, evidently this issue becomes more topical for organizations that are challenged by fast 
and dramatically changing environments. That is why a lot of research on organizational change is focused around such environments, with transition economies among them (Michailova 2000; Alas and Sharifi 2002; Alas and Rees, 2007; Uhlenbruck et al. 2003).

Russia, as a transition country represents a fertile field for this stream of research. The Russian environment has been challenging Russian companies primarily because of its political and economic instability since the end of 1980s (Kets de Vries 2000; Aron 2002). While the general political and economic situation has been stabilizing since the end of the last century, recent years have brought new challenges such as the intensification of competition in many industries or accession to WTO (Rutherford and Tarr 2005). Thus, Russian companies have been facing the strong need for internal changes in order to adapt to external transformations (Khait, Smolko and Ageev 1996; Growth Management 2001). The burden of this task for Russian managers is accentuated by the fact that many of them are unfamiliar with such a volatile situation after training and working in the relatively stable years of the planned economy. In recent years, they have had to acquire knowledge and skills in change management. This observation raises an immediate question about approaches to change management they have been adopting. We propose that some initial insights on the change management problems faced by Russian companies and practices applied by Russian managers can be provided by the change management literature, available in Russian language. On the one hand, it has served as a key initial source of knowledge on organizational change for Russian managers, being the most accessible knowledge tool for leaders of organizations of different regions, sizes and financial states. On the other hand, it reflects the most common topical problems and attitudes to change management in Russian companies. The following discussion summarizes Russian publications on change management during the last two decades. This analysis includes key Russian business and management journals, both practitioner-oriented and academic.

\section{Change management in Russian literature}

At the beginning of the 1990s, due to the overall economic crisis and the competitive situation facing many companies, most of change-related discussion was focused on issues of anti-crisis management and restructuring, or, in other words, on the question 'what needs to be changed?' (that is, change content) (Metcalfe and Afanassieva 2005). Such debates concentrated more around macro-economic or financial management issues, and thus were quite far removed from the common stream of change management literature. At these times, change implementation (that is, change process) issues faded into the background.

In our review of Russian literature, we found that interest towards managerial aspects of organizational change and its implementation leapt at the end of 1990s. We propose that this rise can be linked to the Russian economic crisis of August 1998 that forced many companies into dramatic organizational transformations. At this time, practically oriented business magazines began to publish intensively on change management. Further, international books on managing change in organizations were translated into Russian. For example, Gouillart and Kelly (1995) and Duck (2001) were published in Russian in 2000 and 2002 respectively. Training programmes on the subject started to spring up in the curriculum of business schools and management training companies. Organizational change emerged as one of the 'a-la mode' topics in Russian business press and its popularity remains today.

The planned change model dominates heavily this wave of change management discussion in Russia. It is widely promoted as the best way to implement change in 
organizations, with Lewin (1951) and Kotter (1995) being among its mostly cited proponents. In fact, the issue of planning in management in general has been very topical during last decade in Russia. Some authors claim that Russian leaders did not exercise enough and proper planning, or were focused only on short-term planning (Khait et al. 1996; Growth Management 2001). This problem was explained either by managers' feeling of 'helplessness' and the desire for somebody else to take important decisions, learned during the times of planned economy (Kets de Vries 2000) or by the harsh and turbulent environment of 1990s. This environment forced Russian leaders to concentrate only on short-term survival issues and led many of them to consider planning as irrelevant at all as things changed so quickly (Khait, Smolko and Ageev 1996; Metcalfe and Afanassieva 2005). Thus, many publications on management issues in Russia call for the implementation of planning procedures in the entire range of the company's activities. The planned change model approach fits well into this generic trend.

Despite the current abundance of Russian publications on change management, we observe that most of them are prone to several important drawbacks. First, many of these publications present a limited number of ideas that are borrowed from international publications without adequate discussion of their applicability to the Russian environment. For example, the most discussed topic has been personnel resistance to change (one of the key issues within the planned change approach). In our review, we found out that it was covered in over $30 \%$ of publications on organizational change in popular Russian management and business magazines between 1992 and 2004. Despite the scale of this coverage, most of these writings repeated the same idea, namely that the key problem with change implementation was company's personnel who always resisted change.

Second, this wave of discussion focuses heavily on change implementation issues and pays little attention to the interconnection between change content and change process. Recommendations for managers typically assume that the proposed change implementation approach will work for any type of organizational change with the majority of them promoting a universalistic approach to change. Third, we note that Russian state-of-theart publications on change lack Russian empirical data to support their ideas. Very few domestic researches on the issue of organizational change have been reported (Andreeva 2001; Burmistrov 2003; Shirokova 2003) though we recognize that a limited amount of mostly case-based, empirical data on change management in Russian companies, has been presented by international researchers (Michailova 2000). Nevertheless, these studies have not been widely published in Russia and thus have not been widely used to develop empirically grounded change management approaches and recommendations for Russian managers.

This situation raises another important question. That is, do Western change management practices apply in the Russian context? Or, more specifically, to what extent do planned change approaches work in Russian companies? While some research has been performed on the applicability of Western management practices in Russia in general (Ardichvili et al. 1998; Elenkov 1998; Fey and Denison 2003; May et al. 2005), only a few studies specifically concerned the application of change management practices (Michailova 2000). Interestingly, Michailova discovered that Western managers had troubles with executing change plans in Russian companies for various reasons, ranging from differences in culture to the unpredictable operating environment. While the culture problem is specific for the cases of cross-cultural collaboration, the environmental one is valid for any organization and manager functioning in Russia. These findings are very relevant to our discussion of applicability of the planned change model in Russia and support our call for empirical research on this issue. 


\section{Research goals and hypotheses}

Our analysis identified the need for empirical research on applicability of planned change model, and, more specifically, on its applicability in Russian context. To address this need, our goal was to explore whether the underlying assumption of planned change approach, that is, the idea that organizational change can be planned and controlled for execution of plans, works in Russian companies. For this purpose, we formulated the following hypothesis:

Hypothesis 1. Elements of organizational change do not follow the change agents' plans. The degree of uncontrollability varies depending on the particular content of change.

However, even if this hypothesis was confirmed, it would not be enough to evaluate the applicability of the planned change model, as one can argue that, despite some perceived limitations, planned change interventions increase the efficiency of change management programmes. Hence, this study investigates whether companies with different degrees of change management execution differ in terms of change management efficiency. Taking into account the criticisms of the planned change model discussed above, we hypothesized the following:

Hypothesis 2. The degree of a change plan's execution does not influence the efficiency of the change management programme.

\section{Methodology}

In order to study change content, that is, to explore the elements of organizations' change programmes, we compiled a list of key organizational elements based on a literature analysis (Greiner 1972; Hannan and Freeman 1984; Tushman, Newman and Romanelli 1986; Burke and Litwin 1992; Romanelli and Tushman 1994). This list included the following 11 elements (conventional codes for each element that we use further for the sake of brevity of presentation are given in brackets):

- Corporate mission, ideology (a1)

- Business strategy (a2)

- Organizational structure (a3)

- Distribution of power and authority in the company (a4)

- Organizational culture, key values (a5)

- Management system as a whole (a6)

- Key personnel in the organization (a7)

- Qualitative structure of the staff (skills, knowledge, etc.) (a8)

- Production technology (a9)

- Operational rules and procedures (a10)

- Functional systems (like production, sales and marketing, finance, human resources management systems) (a11)

Following our hypothesis, we looked to identify what organizational elements leaders most often planned to change, as well as what changes had actually happened as a result of the implementation of these plans. For these purposes we used Palmer and Dunford's classification of change results into 'planned', 'partly planned' and 'unplanned' ones (Palmer and Dunford 2002). Combining it with two options for plans (an element was 'planned to change' or 'not planned to change'), we constructed a six-dimensional 
categorization of the correspondence between change plans and results (for example, an element was 'planned to change - changed as planned', 'planned to change - changed partly as planned' etc.). To measure the degree of the change plans' executions, we calculated the share of the organizational elements that changed according to the plans. For these purposes, we considered two of the above six categories (an element was 'planned to change - changed as planned' and 'not planned to change - did not change') as an exact plan execution, and the other four as deviations from plans.

To measure the efficiency of change we used a multifactor qualitative expert evaluation model. The efficiency of change was measured by two factors: the degree to which the goals of change programme had been achieved, and the ratio between expenditure for change implementation programme and benefits gained through it.

\section{Procedures}

We developed a questionnaire using mainly closed multiple choice questions and covering issues on change content (plans and results), change implementation process and change programme efficiency, as well as company and situational characteristics. The questionnaire was pilot-tested with a number of experts. The follow-up interviews with these experts indicated that the multiple-choice questions included all potential options and suggested some minor improvements in questions' wordings and format to ensure they will be properly understood. Samples of the questions from our questionnaire are provided in Table 1.

\section{Respondents}

Our respondents within this research were management consultants. We chose this 'indirect' group of respondents as we found that potential direct experts (company leaders and/or change agents) were reluctant to disclose information on organizational change programmes on the grounds of confidentiality. The respondents were asked to describe the change programme in a company in which they had witnessed changes and about which they had sufficient knowledge. Therefore, our research involved two samples: one of the experts and one of the companies involved.

The sample of experts consisted of 59 management consultants from various regions of Russia; $18 \%$ of them resided in Moscow, $43 \%$ in Saint Petersburg, and the rest in various Russian cities including Arkhangelsk, Vladivostok and Novorossiysk. The majority of the experts had been working for more than three years as management consultants. Thus, we assumed that they possessed sufficient experience to assess the situation in the company objectively. A total of $83 \%$ of the experts held a post external to the organization, which means they were relatively independent and unprejudiced in their assessment.

The sample of companies consisted of the 59 organizations selected by the sample of experts. While safeguarding the companies' anonymity, we are able to report a series of their characteristics. Companies with Russian capital (76\%) and Russian management $(98 \%)$ dominate our sample. The companies of the sample varied greatly in their size, with the three largest groups being companies employing 100-500 people (36\%), 30-100 people $(22 \%)$ and $1,000-5,000$ people (18\%). Regarding industry, companies providing services and production companies were almost equally well represented. 'Young' companies founded after 'perestroika' made up $61 \%$ of the sample, and companies of 6-10 years and older than 20 years represented the largest age distribution groups. In our opinion, this profile of companies corresponds to the dynamics of launching enterprises in Russia over 
Table 1. Samples of questions from our research questionnaire.

E1. Please indicate what changes have happened as a result of change programme implementation and evaluate the degree of their 'intentionality':

\begin{tabular}{l} 
Was it intended? What was changed in fact? \\
\hline Corporate mission, ideology \\
Business strategy \\
Organizational structure \\
Distribution of power and authority \\
in the company \\
Organizational culture, key values \\
Management system as a whole \\
Key personnel in the organization \\
Qualitative structure of the staff \\
(skills, knowledge, etc.) \\
Production technology \\
Operational rules and procedures \\
Functional systems (like production, \\
sales and marketing, finance, \\
human resources management systems) \\
Other (please, indicate what) \\
$\quad$...............................................................
\end{tabular}

E2. How could you evaluate the results of implemented change from the point of view of the achievement of goals, set for the change program by the company leader? Please indicate to which degree the goals set were achieved.

\begin{tabular}{|c|c|c|c|c|c|c|c|}
\hline $\begin{array}{c}\text { Goals are not } \\
\text { achieved at all }\end{array}$ & $0 \%$ & $20 \%$ & $40 \%$ & $60 \%$ & $80 \%$ & $100 \%$ & $\begin{array}{c}\text { Goals are } \\
\text { fully achieved }\end{array}$ \\
\hline
\end{tabular}

the past two decades when the majority of new entrepreneurial companies were founded in the period between the 1991-1992 and 1998 crises.

We note that a limitation of our sample is the fact that the majority of companies have in some way used the services of management consultants. We suggest that companies using consultants' services do not possess any common organizational features. First, the demand for consulting services is large today, which is determined to a great extent by a specialized economy where it is cheaper to buy specialists' services for short-term projects aimed to solve specific problems, than to employ them on a permanent basis. Second, consultants' services available at the market vary greatly in their content and price, which makes them attractive and accessible to a wide range of companies. Thus, Russian companies from all industry branches - large and small, successful and not so successful, solvent and insolvent - resort today to consultants (Krashenko 2004). On this basis, we suggest that the highlighted limitation of our sample does not substantially affect the validity of our conclusions.

\section{Findings}

\section{Change content: plans and results}

In testing our hypothesis, we aimed to discover (1) what organization elements were targeted by the change programmes (plans), (2) what changes actually took place (results) 


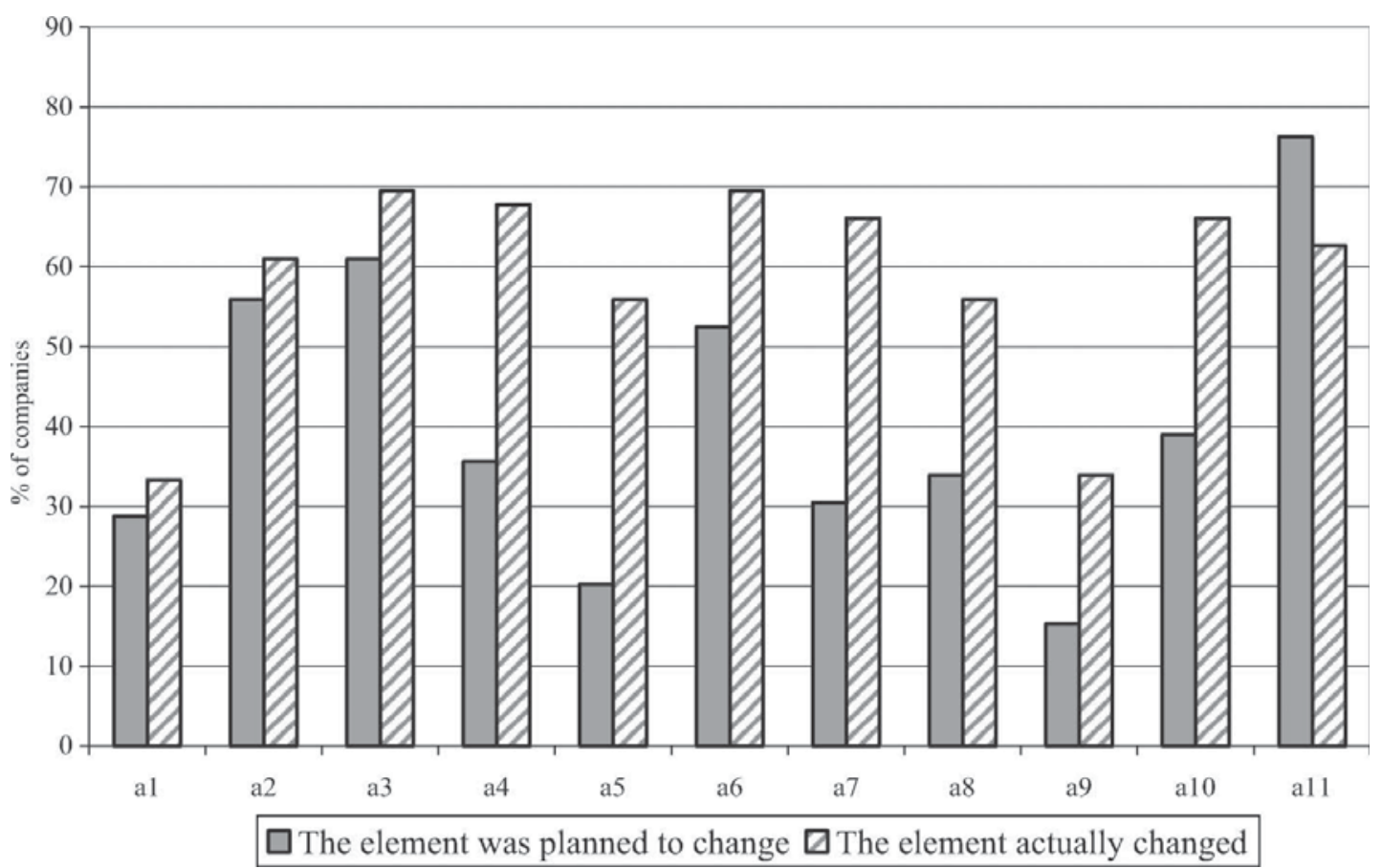

Figure 1. Planned and actual changes in various organizational elements.

and (3) what the difference was between (1) and (2). Figure 1 presents some of the answers to these questions. As one can see, in the majority of cases $(76 \%)$ companies' leaders were interested most in changing functional systems (a11), which comprise marketing, sales, finance and HR management systems. An additional qualitative analysis has shown that among functional systems Russian managers focused on transforming marketing, sales and finance management functions. The changes in organization structure (a3), strategy (a2) and management system as a whole (a6) come next (in 50-60\% of cases). Organizational culture (a5) and technology (a9) are the elements the leaders were least interested in changing.

Turning to what actually happened as a result of the change intervention, one can see that the actual change is greater than planned for the majority of organizational elements. This means that for many companies certain changes were unexpected. For instance, changes in organizational culture (a5), distribution of power and authority (a4) and key personnel (a7) came as a surprise to more than 30\% of companies (differences between bars on Figure 1). To make this comparison more vivid, we calculated the ratio between planned and resultant changes. Changes in distribution of power and authority (a4), key personnel (a7) and technology (a9) took place more than twice as often as planned. Organizational culture (a5) leads this list, having changed 2.8 times more often than planned.

Despite providing some interesting insights, the comparisons presented in Figure 1 consider all the companies taken together without taking into account the dynamics of individual companies. Hence, we carried out a more detailed analysis, taking into account the plan and fact dynamics of each studied company. This analysis is presented at Figure 2.

Figure 2 shows that the distribution of power and authority (a4), organizational culture (a5) and key personnel (a7) deviated from the leader's change plans most often (categories 3-6 all together, 'dark' part of the figure) - in over 50\% of all the cases we have studied. Mission (a1), technology (a9) and strategy (a2) proved to be the opposite (in descending order): these changes coincided with leaders' plans in $70-80 \%$ of cases. 


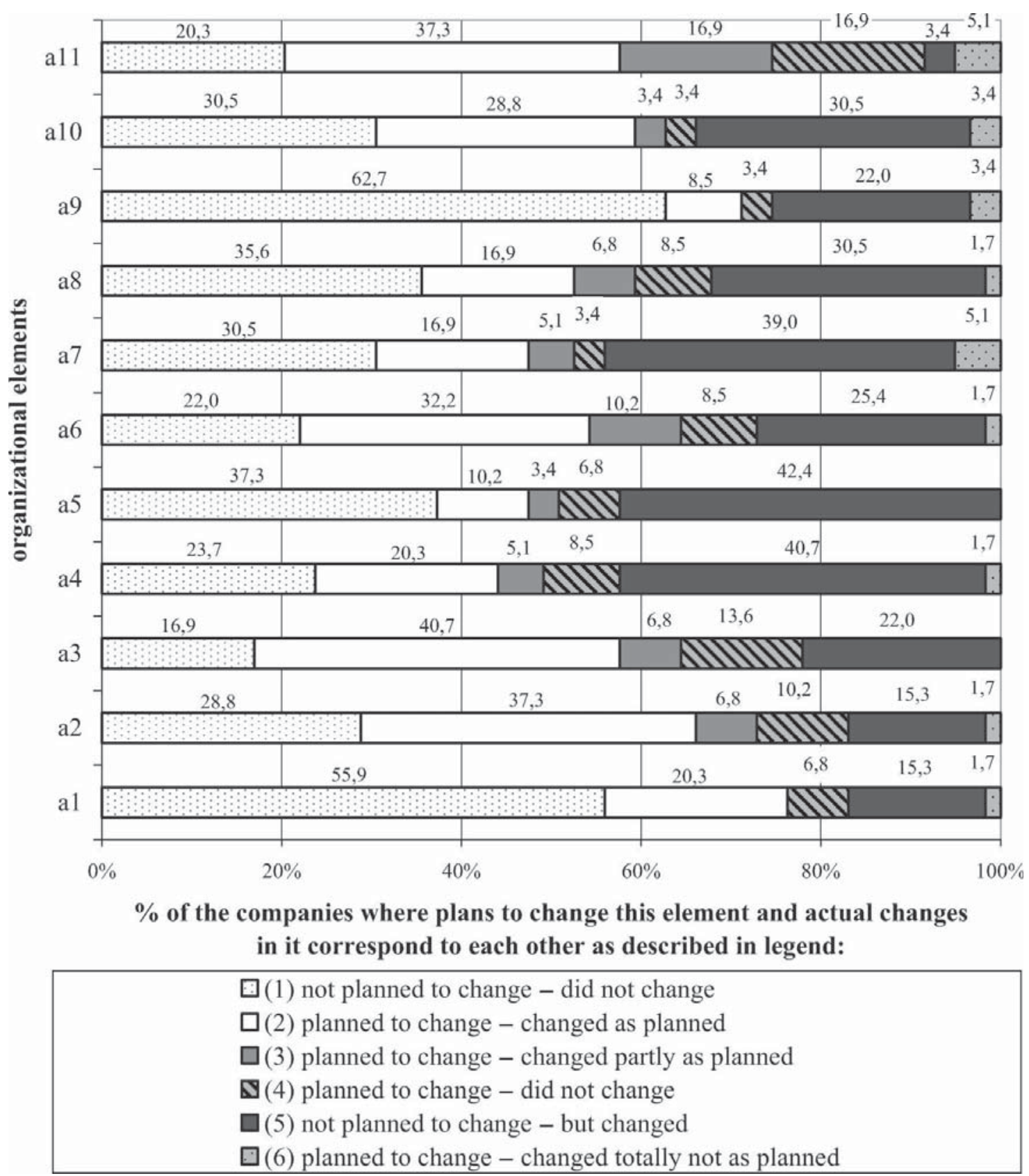

Figure 2. Correspondence between planned and actual changes.

We consider category 3 ('changed partly as planned') as a 'light' degree of discrepancy and thus being of less interest for our research purposes. Cases from category 6 ('planned to change - changed totally not as planned') happened to be very rare in our sample, so we omit them from further discussion and focus on categories 4 ('planned to change - did not change') and 5 ('not planned to change - but changed'). Functional systems (a11) stand prominent among the elements which did not change despite the plans (category 4) (16.9\% of cases). They are followed by organization structure and strategy, which remained unchanged in $13.6 \%$ and $10.2 \%$ of cases respectively. This means that these elements did not change despite receiving the leader's attention from the very beginning of the change intervention. This may have happened either because priorities and goals had changed (but our analysis showed that such cases were infrequent) or, perhaps more perplexing for 
change agents, because the efforts they made failed to bring about desired results. That is why we labelled this group of organizational elements 'unmanageable'.

The foremost among organizational elements, which were not initially meant to change but have changed 'on their own' (category 5, presented in black) are organizational culture (a5, 42.7\% of cases), power and authority distribution (a4, 40.7\%) and key personnel (a7, $39 \%)$. Qualitative structure of the staff $(\mathrm{a} 8,30.5 \%)$ and operational rules and procedures $(\mathrm{a} 10,30.5 \%)$ come next. We labelled this group of organizational elements 'uncontrollable'. We suggest that it represents the greatest potential 'danger' for the change agents among various types of deviations from plans as it includes elements totally left out of their attention.

In summary, the above findings support our hypothesis 1 by demonstrating that the outcomes of organizational change programmes, at least within our sample, are often not the anticipated outcomes of the change intervention strategy.

\section{Change plans' execution and change efficiency}

For sound evaluation of this conclusion, it is necessary to understand whether the degree to which change plans were executed somehow influenced the efficiency of change programmes. Within our data, we did not discover any correlations between the degree of change plans' execution and the two parameters that we employed to evaluate change programme efficiency, that is, the level of achievement of the change programme goals and the cost/benefits ratio. Hence, our hypothesis 2 is also supported within our research sample.

Finally, we found that in the cases where organizational culture changed as a result of change programme implementation, the change efficiency achieved a higher assessment along both parameters, than in the programmes where no change of organizational culture was reported by the experts.

\section{Discussion and implications}

Analysis of our research data has shown that results of organizational change programmes often deviate from initial plans of change agents, with some of the organizational elements targeted to change being sometimes 'unmanageable' and others being frequently 'uncontrollable'. Moreover, we found that whether the change programme plans were achieved or not does not matter for the change programme efficiency. Thus, our research results suggest that one of underlying assumptions of planned change model is invalid for Russian companies we studied. What factors may serve as potential explanations of such a situation for change management in Russian companies? Are there any specific economic, cultural or other factors that may explain our findings?

One explanation can be related to the unstable and unpredictable environment in which Russian companies operate (Metcalfe and Afanssieva 2005; May, Puffer and McCarthy 2005). In such situations, a manager's capability to formulate realistic plans and control for their exact execution may be limited by external forces. Another causal explanation may be linked to the very low level of change management skills among Russian managers, due to the lack of special education or experience in change management (Michailova 2000). Yet our experts' evaluations of the efficiency of change programmes they described and of the adequateness of decisions made by managers lead us to reject this explanation of the findings. 
Can our results be explained by specifics of Russian culture? We suggest that among Hofstede's cultural dimensions (Hofstede 2001) it is uncertainty avoidance that concerns the problem of planning and control. Some authors claim that Russia is 'high' on this index (Elenkov 1998), meaning that Russians fear uncertainty and ambiguity and strive to decrease them by all possible means. From this standpoint, the interpretation of our findings is somewhat ambiguous. On the one hand, high uncertainty avoidance might mean that Russian change agents are very focused on planning as it reduces uncertainty. This perspective suggests that the discrepancy we found between change plans and results in our sample was not due to the low level of plans' execution but rather due to superfluous and unrealistic over-planning. Yet, on the other hand, one would anticipate that that in aiming to decrease uncertainty, Russian managers would exert control over the execution of their plans and thus minimize deviations from change plans.

Another cultural dimension is relevant to the discussion of findings. If we consider OD and its planned change model as having USA roots, then we may claim that it is based on the belief in an individual's power to control the situation (Boyacigiller and Adler 1991). Russian managers, however, are commonly reported to rely on the opposite idiosyncrasy, often feeling incapable of implementing their decisions (Kets de Vries 2000; Alas and Rees 2006). If this were the case, one would not expect to see in our data that high level of planning as compared to the achieved results; plans do not make much sense if a planner does not believe in his/her capability to implement them. To summarize, this discussion suggests that cultural factors do not account for our findings, at least not fully.

Turning to the situation with planning and controlling change in particular organizational elements, we have witnessed that 'soft', human-factor related organizational elements happen to be the least 'controllable' in Russian companies. One of the explanations for that can be derived from our findings as they demonstrate that Russian managers do not pay sufficient attention to such organizational elements on the change planning phase (Ardichvili 1998). For example, our findings suggest that Russian managers tend to underestimate organizational culture as one of the essential elements of organization and its close interdependence with other organizational elements. The question then arises as to why these 'soft' issues fall away from the field of managers' interest. Some authors claim that environmental pressures force Russian managers to focus on the short-term tangible results (Fey, Nordahl and Zatterstrom 1999). It is probably for this reason that human-related issues become less of a managerial priority, as outcomes of such efforts are less evident and more distant in time.

We also found that functional systems, organizational structures and strategies are 'unmanageable' for Russian managers, though from a first glance at our list of organizational elements they seem to be among the most easily administered by company leaders. We suggest that this result is consistent with our findings on the 'uncontrollability' of 'soft' organizational issues. Neglecting the complex nature of organization where all elements are closely interrelated by underestimating the importance of human-related issues within the change programme may lead to failures in exerting managerial power even on the most 'technical' aspects of change efforts.

Our findings allow us to formulate some recommendations for change agents functioning in Russian companies. We suggest that Russian managers need to acknowledge the limitations of planned change model and allow for a more flexible and emergent approach. This remark might also be relevant to those who are in a position to evaluate results of change programmes (for example, for company owners) as it means that exact change plan execution should not be used as a criterion for assessment of the change agent's work or at least, it should not be the only one. We propose that more consideration 
of 'soft' organizational elements during all the process of change intervention is needed in the context of Russia.

Nevertheless, are the described above findings country specific? We believe that with certain limitations they may be relevant to a wider context. Environmental turbulence is not the privilege of Russia and other transitional economies; it is recognized as one of the key challenges for many organizations worldwide. Moreover, our research involved mostly 'internal' organizational elements that are in the short-term less sensitive to environmental jolts. Thus, Russian-specific explanations for the low level of the change plans' execution in our data are not particularly satisfactory. We have demonstrated above that the lack of change management skills and cultural factors cannot fully account for our results.

Thus, we suggest that our findings can be treated as supporting the view relating to the limited controllability of organizational change processes and, consequently, challenging the validity of the planned change model. On the wider conceptual level, our findings might be seen as refuting to a large extent the validity of a deterministic approach to the organization and a control-based understanding of management. Rather we see the findings as providing a degree of support for the recent ideas on improvisational and emergent approaches to change management (Weick 1998; Weick and Quinn 1999; Palmer and Dunford 2002).

We are far from claiming that a planned change approach is completely irrelevant in the modern world, or that planning is an obsolete function among change management activities. However, on the basis of these findings, we suggest that managers and other change agents should not be over focused on change planning activities as many issues emerge in unplanned ways during change implementation process.

Finally, we conclude that these findings are interesting in the light of the two problematic issues in contemporary change management literature. First, current organizational change writings are heavily focused on change implementation processes (McGuinness and Morgan 2003). Though implementation is clearly important, we agree with Barnett and Carroll (1995) that such a focus on the process of change ('how to change something') and lack of attention to the related content of change ('what to change') hinders a deeper understanding of the complex phenomena of organizational change and, respectively, from the development of valid recommendations for managers. Our research provides vivid evidence that change content matters and thus contributes to a call for a more balanced approach to change management research and practice. This is all the more important given that the socio-cultural and political institutional environments in transition are represented by fragility, ambiguity and uncertainty for all stakeholders.

Second, as we have mentioned above, organizational change literature suffers from the prescriptive tone of its recommendations (Burnes 1996). The more sophisticated choice/ contingency approaches (Stace and Dunphy 1991; Marshak 1993; Burnes 1997) have to date failed to gain widespread popularity, perhaps due to a lack of the empirical evidence surrounding their efficacy. Our findings contribute to the field by demonstrating that change content issues (question 'what needs to be changed?') have to be considered as one of the factors that influence informed choice of the change implementation methods. Thus, in broad terms, the findings support contingency approaches to change management. Moreover, we suggest that change content has to be incorporated into contingency models of change as one of the important organizational contingencies.

Yet, our research should be considered only as a contribution towards defining the limits of the applicability of the planned change model and the development of more 
sophisticated contingency approach. Future research based on the bigger samples of companies and involving companies functioning in different contexts (for example, in different countries or industries) will contribute to a more comprehensive understanding of the limitations of the planned change model and, consequently, lead to more informed and efficient change management practices, both in Russia and internationally.

\section{References}

Alas, R., and C.J. Rees. 2006. Work-related attitudes, values and radical change in post-socialist contexts: a comparative study. Journal of Business Ethics 68, no. 2: 181-9.

, and S. Sharifi. 2002. Organizational learning and resistance to change in Estonian companies. Human Resource Development International 5, no. 3: 313-31.

Andreeva, T. 2001. Antikrizisnoe upravlenie personalom v Rossii (analiz rezultatov oprosa 25 peterburgskih kompanij) ('Anti-crisis human resources management in Russia (analysis of interviews in 25 St Petersburg companies'). Rossijski management: teorija, praktika, obrazovanie 1: $95-106$.

Ardichvili, A., R.N. Cardozo, and A. Gasparishvili. 1998. Leadership styles and management practices of Russian entrepreneurs: implications for transferability of Western HRD interventions. Human Resource Development Quarterly 9, no. 2: 145-55.

Armenakis, A., and A. Bedeian. 1999. Organizational change: a review of theory and research in the 1990s. Journal of Management 25, no. 3: 293-315.

Aron, L. 2002. Making sense of a revolution. Russian Outlook, Fall: 1-10.

Barnett, W., and G. Carrol. 1995. Modeling internal organizational change. Annual Review of Sociology 21, no. 1: 217-36.

Beer, M., R.A. Eisenstat, and B. Spector. 1990. Why change programmes don't produce change. Harvard Business Review 68, no. 6: 158-66.

Berger, A. 1992. Towards a framework for aligning implementation change strategies to a situationspecific context. International Journal of Operations and Production Management 12, no. 4: 32-44.

Blake, R.R., and J.S. Mouton. 1969. Building a dynamic corporation through grid organization development. Reading, MA: Addison-Wesley Publishing Company.

Boyacigiller, N.A., and N.J. Adler. 1991. The parochial dinosaur: organizational science in a global context. Academy of Management Review 16, no. 2: 262-90.

Burke, W., and G. Litwin. 1992. A causal model of organizational performance and change. Journal of Management 18, no. 3: 523-45.

Burmistrov, A. 2003. Kak organizovat' provedenie izmenenij. Opyt predprijatij Sankt-Peterburga ('How to implement changes. Experience of St. Petersburg companies'). Top-Manager 2: 30-6.

Burnes, B. 1996. No such thing as ... a 'one best way' to manage organizational change. Management Decision 34, no. 10: 11-18.

Burnes, B. 1997. Organizational choice and organizational change. Management Decision 35, no. 10: 753-9.

Cummings, T.G., and E.F. Huse. 1989. Organization Development and Change. St Paul, MN: West Publishing.

Dooley, K., and A. Van de Ven. 1999. Explaining Complex Organizational Dynamics. Organization Science 10, no. 3: 358-72.

Duck, J. 2001. The change monster: In The Human Forces That Fuel or Foil Corporate Transformation and Change. New York: Crown Business.

Elenkov, D.S. 1998. Can American management concepts work in Russia? A cross-cultural comparative study. California Management Review 40, no. 4: 133-56.

Fey, C.F., and D. Denison. 2003. Organizational culture and effectiveness: Can American theory be applied in Russia? Organization Science 14, no. 6: 686-706.

-, C. Nordahl, and H. Zatterstrom. 1999. Organizational culture in Russia: The secret to success. Business Horizons 42, no. 6: 47. 
French, W.L., and C.H. Bell Jr. 1995. Organization development. Behavioral science interventions for organizational improvement. Englewood Cliffs, NJ: Prentice Hall, Inc.

Gouillart, F.J., and J.N. Kelly. 1995. Transforming the Organization. New York: McGraw-Hill, Inc.

Greiner, L. 1972. Evolution and revolution as organizations grow. Harvard Business Review 50, no. 4: $37-46$.

Growth Management 2001: The Experience of Successful Russian Industrial Companies. 2001. Research report, ALT Research and Consulting company, St Peterbsurg, Russia. http:// www.altrc.ru/consult/mr2001/gm2001.shtml (accessed July 2007).

Hannan, M.T., and J. Freeman. 1984. Structural inertia and organizational change. American Sociological Review 49, no. 2: 149-64.

Hendry, C. 1996. Understanding and creating whole organizational change through learning theory. Human Relations 49: 621-41.

Hofstede, G. 2001. Culture's Consequences: Comparing Values, Behaviors, Institutions and Organizations Across Nations. 2nd ed. Thousand Oaks, CA: Sage.

Huy, Q., and H. Mintzberg. 2003. The rhythm of change. MIT Sloan Management Review 44, no. 4: 79-84.

Kets De Vries, M.F.R. 2000. A Journey into the 'Wild East': Leadership Style and Organizational Practices in Russia. Organizational Dynamics 28, no. 4: 67-82.

Khait, I., I. Smolko, and S. Ageev. 1996. Management rosta 1996. Opyt uspeshnih rosskiskih promyshlennih predpijatij ('Growth Management: Experience of Successful Russian Manufacturing Enterprises'). Expert, 3 June.

Kotter, J. 1995. Leading change: Why transformation efforts fail. Harvard Business Review 73, no. 2: 59-67.

Krashenko, L. 2004. Protivostojanie: Karta rossijskogo konsaltinga ('Contradistinction: Russian consulting map'). Expert 7, no. 410: 25-8.

Lewin, K. 1951. Field theory in social sciences. New York: Harper \& Row.

Lichtenstein, B.B. 2000. Self-organized transitions: a pattern amid the chaos of transformative change. Academy of Management Executive 14, no. 4: 128-41.

Lippitt, R., J. Watson, and B. Westley. 1958. The Dynamics of Planned Change. New York, NY: Harcourt, Brace \& World.

Marshak, R. 1993. Lewin meets Confucius: a review of the OD model of change. Journal of Applied Behavioral Science 29, no. 4: 393-415.

May, R.C., S.M. Puffer, and D.J. McCarthy. 2005. Transferring management knowledge to Russia: A culturally based approach. Academy of Management Executive 19, no. 2: 24-35.

McGuinness, T., and R.E. Morgan. 2003. Organizational change capability: the theoretical construct and its operational measurement. In Developments in Marketing Science, Proceedings of the Academy of Marketing Science Conference, Washington DC, USA.

Metcalfe, B.D., and M. Afanassieva. 2005. The woman question? Gender and management in the Russian Federation. Women in Management Review 20, no. 6: 429-45.

Michailova, S. 2000. Contrasts in culture: Russian and Western perspectives on organisational change. Academy of Management Executive 14, no. 4: 99-112.

Palmer, I., and R. Dunford. 2002. Who says change can be managed? Positions, perspectives and problematic. Strategic Change 11, no. 5: 243-51.

Romanelli, E., and M. Tushman. 1994. Organisational transformation as punctuated equilibrium: an empirical test. Academy of Management Journal 37, no. 5: 1141-66.

Rutherford, T., and D. Tarr. 2005. Russia's WTO Accession: What are the macroeconomic, sector, labor market and household effects? Working paper, World Bank. www.worldbank.org/trade/ russia-wto (accessed July 2007).

Sevier, R. 2003. Overcoming internal resistance to change. University Business 6, no. 7: 23-4.

Shirokova, G. 2003. Podhodi k provedeniju izmenenij v rossiiskih kompanijah ('Approaches to change management in Russian companies'). Vestnik St. Peterburgskogo Gosudarstvennogo Universiteta, Serija Management 3: 76-95. 
Stace, D., and D. Dunphy. 1991. Beyond traditional paternalistic and developmental approaches to organizational change and human resource strategies. International Journal of Human Resource Management 2, no. 3: 263-83.

Thietart, R., and B. Forgues. 1995. Chaos theory and organization. Organisation Science 6, no. 1: $19-31$.

Tushman, M., W. Newman, and E. Romanelli. 1986. Convergence and Upheaval: Managing the Unsteady Pace of Organizational Evolution. California Management Review 29, no. 1: 29-44.

Uhlenbruck, K., K.E. Meyer, and M.A. Hitt. 2003. Organizational transformation in transition economies: Resource-based and organizational learning perspectives. Journal of Management Studies 40, no. 2: 257-82.

Van de Ven, A., and M. Poole. 1995. Explaining development and change in organizations. Academy of Management Review 20, no. 3: 510-40.

Weick, K. 1998. Improvisation as a mindset for organizational analysis. Organization Science 9, no. 5: $543-55$.

., and R. Quinn. 1999. Organisational change and development. Annual Review of Psychology 50, no. 1: 361-86. 